\title{
Mensaje del Presidente de la SMNyCT sobre el Consenso 2020 en Terapia Nebulizada en México
}

\author{
Message from the President of SMNyCT on the 2020 \\ Consensus on Nebulized Therapy in Mexico
}

\author{
Adrián Rendón* \\ *Presidente 2019-2021, Sociedad Mexicana de Neumología y Cirugía de Tórax (SMNyCT).
}

La Sociedad Mexicana de Neumología y Cirugía de Tórax está celebrando 81 años de promover la salud respiratoria en México. El alcance de nuestra sociedad originalmente se limitaba a las sedes neumológicas en la capital del país. En la actualidad, su influencia abarca a otras sociedades respiratorias no sólo nacionales, sino también del ámbito internacional. Al incrementar su visibilidad, la SMNyCT se ha vuelto punto de referencia para otras especialidades afines y empieza a tener un impacto hacia la sociedad civil, cumpliendo así con la ineludible responsabilidad social inherente a la actividad de cualquier asociación médica.

Las enfermedades respiratorias son consideradas como un serio problema de salud pública. Asma, EPOC, infecciones respiratorias, tuberculosis y cáncer han sido denominadas las «5 grandes» por el gran número de enfermos que las padecen en el mundo, causando tremenda morbilidad e inaceptable mortalidad.

La terapéutica de las enfermedades respiratorias ha evolucionado rápidamente no sólo con la disponibilidad de nuevos medicamentos, sino también con un mejor entendimiento de cómo usarlos de manera más efectiva. Los medicamentos disponibles para padecimientos respiratorios pueden ser administrados por vía oral o parenteral, pero es innegable que la administración directa a través del aparato respiratorio, la vía inhalada,

Correspondencia:

Adrián Rendón

Correo electrónico: carmencano09@gmail.com

Recibido: 26-11-2020; Aceptado: 07-12-2020.

Citar como: Rendón A. Consenso 2020 en Terapia Nebulizada en México. Mensaje del Presidente de la SMNyCT. Neumol Cir Torax. 2021; 80 (Supl. 1): s4-s5. https://dx.doi.org/10.35366/98505 ha jugado un papel preponderante desde los inicios de nuestra especialidad y lo sigue haciendo en el manejo de los padecimientos que afectan tanto las vías aéreas como el parénquima pulmonar.

La terapia nebulizada tiene múltiples aplicaciones, es útil en padecimientos observados a temprana edad y en los propios de la edad avanzada. La lista actual de etiologías que se benefician de la administración de medicamentos inhalados sigue creciendo, asma, EPOC, bronquiectasias, fibrosis quística, micobacteriosis, micosis, infecciones bacterianas son algunas de las enfermedades en las que el tratamiento de elección debe ser a través de la vía aérea. Asimismo, la lista de medicamentos que pueden administrarse con terapia nebulizada es larga: broncodilatadores, esteroides, antibióticos, antimicóticos, antivirales, mucolíticos, terapia enzimática, surfactante, anestésicos, diuréticos, sales como el sulfato de $\mathrm{Mg}$ y soluciones simples como la salina normal o la hipertónica.

Y no podemos dejar de mencionar el rol primordial de la terapia nebulizada en pacientes que necesitan asistencia ventilatoria, tanto invasiva como no invasiva. Es importante recalcar que no sólo los casos de enfermedades respiratorias de base se pueden beneficiar de la terapia nebulizada; muchos enfermos con padecimientos inicialmente no respiratorios, como las enfermedades crónico-degenerativas, al descompensarse, también se pueden beneficiar en gran medida cuando usan esta estrategia de manejo, lo cual amplía el espectro de dicha terapia.

A pesar del gran avance que se ha tenido con el diseño de ingeniosos dispositivos inhaladores de uso personal, cada vez más eficientes y fáciles de usar, principalmente en el manejo del asma y de la EPOC, el uso de la terapia nebulizada no sólo no ha podido ser desbancado, sino que continúa siendo una herramienta primordial en el manejo de sujetos incapaces de usar dichos dispositivos o en aquéllos que, por la severidad de su padecimiento, ameritan la 
administración eficiente de medicamentos inhalados sin margen de error.

Por ser tan versátil, la terapia nebulizada es usada de manera amplia en casi cualquier institución pública o privada donde se atiendan casos con padecimientos respiratorios. Desafortunadamente, muchos de los protocolos para su uso se han pasado de boca en boca y se han implementado bajo la práctica de «usos y costumbres», algunas veces sin la aplicación correcta de las directrices que permiten obtener el máximo beneficio, tanto para el manejo hospitalario en la sala general y en urgencias como en la terapia intensiva. Se podría decir lo mismo de su creciente uso para el manejo domiciliario de algunas patologías.

Aunque el uso de la terapia nebulizada pertenece al campo del especialista en enfermedades respiratorias, también puede y debe ser aplicada de manera correcta por cualquier colega que tenga a su cargo un enfermo que se beneficie de usarla.

Por esto, este primer Consenso 2020 en Terapia Nebulizada en México ha cubierto una gran necesidad ya existente, pero agudizada a un grado superlativo en estos momentos críticos en nuestro país, en los que el manejo de las enfermedades respiratorias ha tenido que ser abordado por prácticamente todos los profesionales de la salud, sin importar su actividad previa a la pandemia de COVID-19.

Bajo el liderazgo de la Dra. María del Carmen Cano Salas, un grupo de reconocidos expertos que representan a prestigiosas instituciones se dio a la tarea de preparar este consenso, donde después de revisar la literatura más reciente, presentan sus conclusiones de manera ágil y didáctica siguiendo directrices científicas ampliamente estandarizadas.

Este documento revisa de principio a fin el uso de la terapia nebulizada. Dentro de los temas abordados incluyen: qué son los aerosoles y su comportamiento en la vía aérea; y cuáles medicamentos se pueden nebulizar y sus indicaciones. Nos describe los diferentes equipos para nebulizar actualmente disponibles y cómo usarlos, tanto en el paciente intubado como en el no intubado. Los autores también nos explican cómo resolver los problemas más comunes a los que nos enfrentaremos durante la terapia nebulizada y proporcionan información indispensable para la educación que debe recibir nuestro paciente.

Por último, no podría faltar un capítulo dedicado a la bioseguridad durante el uso de terapia nebulizada en los casos con COVID-19, recomendaciones por demás necesarias en estos tiempos en los que proteger al personal de salud es una prioridad.

En resumen, podemos decir que el lector encontrará aquí respuesta a la mayor parte de las dudas que pudiera tener sobre la utilidad de la terapia nebulizada en cualquier tipo de paciente que la requiera. Los conceptos básicos son desmenuzados y analizados a profundidad, pero son seguidos de recomendaciones prácticas y fáciles de implementar. Su contenido seguramente será muy útil para el especialista experto en padecimientos respiratorios: el neumólogo, el intensivista, el terapista respiratorio y el personal de enfermería; pero sin duda alguna también servirá para el personal de salud en formación y para todos los colegas que, en su quehacer diario, manejan a enfermos respiratorios y requieren una orientación práctica generada por expertos, la cual puedan trasladar fácilmente a sus pacientes.

Por su oportunidad, su brillante desarrollo y su completo contenido, le auguro y deseo un gran éxito a este Consenso 2020 en Terapia Nebulizada en México, el cual sin duda servirá para que los profesionales de la salud en México consideren dentro de su arsenal terapéutico esta modalidad y la aprovechen al máximo, beneficiando en lo más posible a quien más lo necesita: nuestros enfermos.

Mis felicitaciones a todos los autores e instituciones participantes que, aun en estos difíciles tiempos de pandemia, tuvieron la entereza y el coraje para continuar trabajando y terminar este proyecto, brindándonos con su esfuerzo un documento por demás útil y necesario, el cual será un referente en su campo, difícil de mejorar en futuras ediciones.

Enhorabuena. 